\title{
Economic development of a region with a unique ecological system
}

\author{
Larisa Desfonteines ${ }^{1 *}$, Elena Korchagina ${ }^{1}$, and Natalia Strekalova $^{2}$ \\ ${ }^{1}$ St. Petersburg Peter the Great Polytechnic University, 195251, Polytechnicheskaya, 29, St. \\ Petersburg, Russian Federation \\ ${ }^{2}$ Herzen State Pedagogical University of Russia, 191186, Kazanskaya (Plekhanova) st. 6, St. \\ Petersburg, Russian Federation
}

\begin{abstract}
The article considers the possibility of developing the economy of the Arctic zone of the Russian Federation, taking into account the preservation of the ecological system of the region and the national and cultural characteristics of the indigenous population. The analysis of the resource potential of the region is given, recommendations for the development of the region's economy using the labor potential of the population living there are offered. The article analyzes the development of the region and the possibility of creating eco-friendly enterprises, the work of which does not violate the natural balance of the Arctic. The article highlights the main elements of the Arctic economic system that require support at the level of strategic development of the state and determine the key positions in the development of the region. The article considers the constraints and problems that hinder the economic development of the Arctic zone of the Russian Federation and the conditions for preserving the uniqueness of the nature and culture of the indigenous peoples of the region. The potential of the economic development of the region is investigated. Innovative options for the development of the region in combination with modern technologies for preserving the unique ecological system and the identity of the indigenous population are considered. Promising directions of economic development of the Arctic region while preserving the uniqueness of nature and cultural traditions of indigenous peoples are proposed.
\end{abstract}

\section{Introduction}

The Arctic as a special natural zone is interesting and attractive for various sectors of the economy of all countries located on the territory of this natural zone. The richness and diversity of the Arctic nature is an object of national interests of many states. All countries represented in the Arctic consider the use of natural resources as part of their economic development strategy. However, the uniqueness of the natural conditions of this region can be considered an international heritage of all mankind. The history of research and

* Corresponding author: 1ja2@yandex.ru 
development of the Arctic is primarily associated with the development of natural resources.

The Russian Federation has the longest border in the Arctic. The development of the natural resources of the Russian Arctic has a long history. The Arctic zone is of strategic importance for the economy of the Russian Federation [1]. Mineral resources are important not only for the development of the branches of the national economy of Russia, but also represent a promising export potential [2]. In terms of the number of minerals of strategic importance for Russian industry, the Arctic zone is the most important object that needs to be developed taking into account the preservation of natural conditions and the identity of the indigenous population [3].

The Arctic region is a unique nature reserve, the nature of which is an ecological resource that requires careful treatment and maintenance of natural conditions. The Arctic is an element of the global climate system, associated with its other elements-the transport of heat, moisture, salt and water due to the circulation of the atmosphere and the ocean [4]. The spontaneous and uncontrolled development of the natural resources of the region led to a violation of the ecological balance and caused damage to the indigenous population.

\section{Materials and methods}

The richness of the Arctic's natural resources is the basis for the economic development of the countries present in the region. On the one hand, the refusal to develop natural resources is impossible due to the depletion of the potential of the economy of the region and the country as a whole. On the other hand, industrial production in a unique natural system can lead to a violation of the ecological balance. Technogenic impact and industrial expansion can change the traditional way of life of the indigenous population, which will lead to both an outflow of labor resources [5] and a distortion of the cultural heritage of the peoples of the Arctic zone. It can be assumed that the main task in the development of the Arctic region and the development of the economy will be to preserve the uniqueness of the ecological system in combination with the support of traditional folk crafts and the identity of indigenous nationalities [6]. The main purpose of the study was to combine promising directions for the development of the Arctic zone of the Russian Federation and to preserve the uniqueness of the natural and cultural features of the region. The objectives of the study were determined in accordance with the goal:

- to study the promising directions of economic development of the Arctic zone of the Russian Federation;

— identify the problems of anthropogenic and technogenic impacts in the Arctic zone;

- unlock opportunities of development of the Arctic region with the preservation of the natural environment, culture and life of indigenous peoples;

- to present the results of a statistical analysis of current trends in the maintenance and preservation of the Arctic ecological system in the Russian Federation.

To solve these tasks, we used the reports of the Official Statistics Service of the Russian Federation (Rosstat), statistical reports of public opinion research in Russia. Comparative, descriptive and statistical methods of research, as well as the method of analyzing scientific literature.

The statistical data were subjected to a comparative analysis, which allowed us to draw conclusions that correspond to the tasks set.

\section{Results}


The main sources of economic growth in the Arctic region of the Russian Federation are the following:

- development of economic sectors related to the extraction of minerals, which are rich in the region;

- creation of transport chains connected with the activities of the Northern Sea Route, providing industry and the social sphere of the region [7];

- using the human potential of the indigenous peoples inhabiting the Arctic region, expanding and supporting the local population in combination with using the labor potential of the attracted labor force [8];

- preservation and maintenance of the natural environment as a resource of ecological and extreme tourism [9].

The Russian Federation currently produces $91 \%$ of natural gas and $80 \%$ of industrial gas in the Arctic from all gas production in the country. In addition to the diluted gas reserves, almost all undiscovered Arctic gas reserves are located off the coast of Russia. The total value of mineral resources in the bowels of the Arctic regions of Russia exceeds 30 trillion dollars, and two-thirds of this amount is accounted for by energy carriers. And the total value of the explored reserves is 1.5-2 trillion dollars. This indicates a low degree of exploration, and even more so the development of subsurface resources, and does not allow the full use of the natural resources of the Arctic.

Figure 1 shows the percentage of mineral resource development in the Arctic in the Russian Federation.

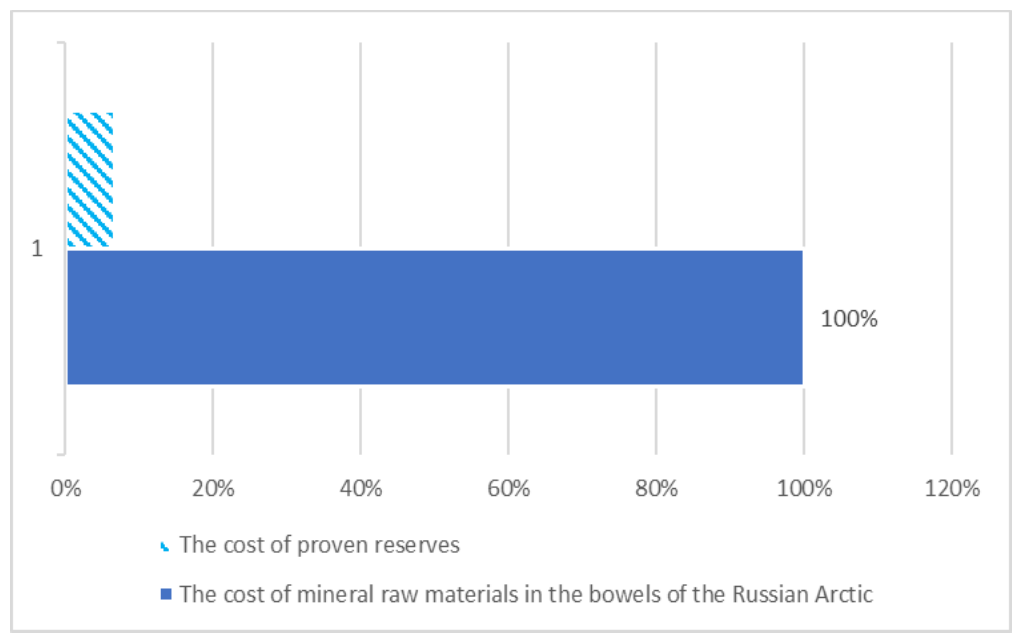

Fig. 1. Percentage development of mineral resources in the Arctic in the Russian Federation

As shown in Figure 1, the percentage of mineral development is only $6.2 \%$ of the estimated reserves. A natural question arises: why are the rich resources of mineral raw materials not used? Technological progress and digitalization of production allows us to develop hard-to-reach regions, severe climatic conditions are leading among the factors limiting the development of natural resources in the Arctic. The second most important factor is the need to develop and use complex and expensive technologies to preserve the unique ecological system of the region. Some of them cannot be used in the conditions of the far North or require specialization that cannot be replicated. If such technologies are developed, there will be investors interested in such developments, and the technological process must be adapted to the ecological system of the Arctic region. The combination of complex natural conditions with the need to preserve a unique ecosystem requires unique technical developments that can only be used in a specific region, only to perform certain 
tasks. There are currently no such scientific and technological developments. In addition, if the projects of the 1980s for the development of the Arctic region are unfrozen, they will be very costly, since it will require significant refinement and improvement of these projects in accordance with new technologies and new demands of society. The third constraint is the lack of a sufficient number of qualified specialists to develop the natural resources of the Arctic in accordance with environmental requirements. The region is also experiencing a shortage of labor resources. Representatives of indigenous peoples are not numerous, and workers who come to the region experience difficulties due to the imperfection of social and living conditions in difficult climatic conditions.

The products produced in the Arctic region provide 11\% of Russia's national income and more than $20 \%$ of all-Russian exports [10]. However, the number of employees operating in Arctic organizations is less than 3\% of the total number of employees in the Russian Federation. This ratio is shown in figure 2.

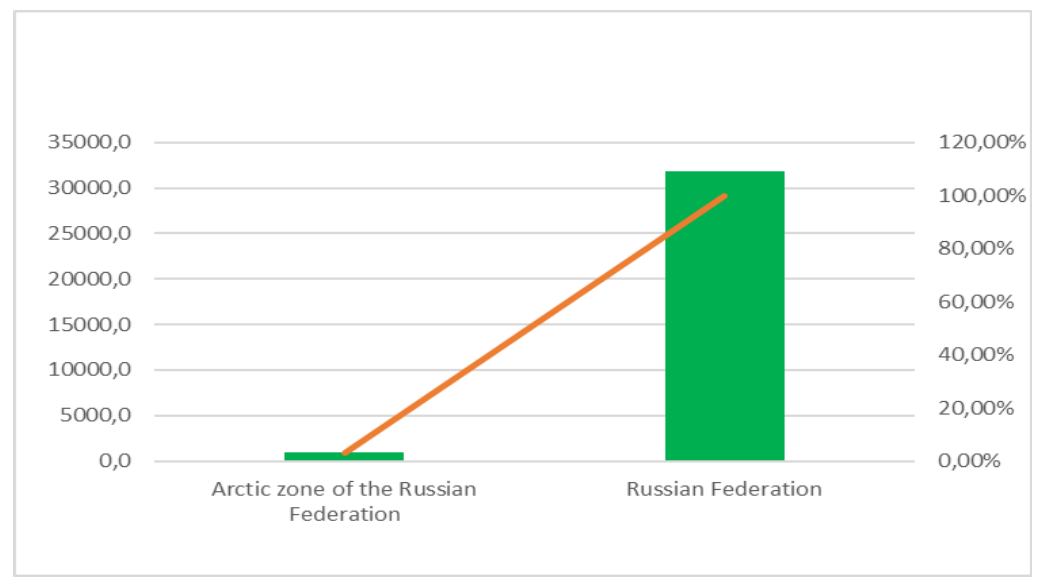

Fig. 2. The number of employees in organizations, operating in the Arctic zone of the Russian Federation.

Figure 2 allows us to conclude that $11 \%$ of the national income is provided by $2.9 \%$ of the working-age population. This fact proves the lack of labor resources in the region. The lack of qualified personnel does not allow the development of technologies in the region that ensure the stability of the environmental and technological balance. The indigenous population of the Russian Arctic does not exceed 200 thousand people [11]. Due to the small number and lack of the required qualifications, the indigenous population cannot meet the requirements of the modern labor market in the region [12]. The centuries - old period of adaptation to extreme natural conditions has determined the specifics of their way of life, the uniqueness of culture and traditions. Most of them continue to use natural resources in traditional ways, preserving their identity. Violation of this way of life can lead to the disappearance of some indigenous peoples. At the same time, the adaptation of the indigenous population to the harsh climatic conditions of the region allows us to consider this small social group as a resource for the development of the Arctic [13]. As a positive trend, it can be noted that the life expectancy of the population in the Arctic has increased. The life expectancy of the indigenous population of the Arctic has always been lower than in Russia. Currently, there is an increase in the life expectancy of the population. So the life expectancy of people in the Arctic zone in 2014 was 70.15 years, in 2018 - an increase to 72.39 years was noted [14].

The Arctic is of interest to fans of extreme tourism [15]. The Russian Federation has unique recreational resources in the Arctic. The Arctic Economic Council of Russia, along with energy and infrastructure, has created a working group on tourism. However, the 
number of offers on the tourist services market is small. It offers almost the only tourist product-a cruise to the North Pole. This offer is unique and is an exclusive Russian tour.

The development of ecological and cruise tourism in the Arctic depends on the modernization of transport hubs. Of particular importance is the Northern Sea Route, which began operating in the mid-30s of the twentieth century. The discovery of the Northern Sea Route was the result of numerous research works that were carried out over several centuries in the Russian Empire. The goal was to create a transport corridor for the supply of goods to the regions of the far North. The modern functions of the Northern Sea Route have changed, and cruise tourism and extreme tourism in the Arctic can be added to them. The use of the Northern Sea Route for the development of tourism in the Arctic can make a significant contribution to the economy of the region [16].

\section{Discussion}

The awareness of the inextricable link between the economic development of the Arctic region and the preservation of the unique ecological system and the cultural heritage of indigenous peoples led to a new state strategy for the development of the Russian Arctic. The new approach to the development of the Arctic is reflected in the state document "Strategy for the Development of the Arctic Zone of the Russian Federation and Ensuring National Security for the period up to 2035", approved by Presidential Decree No. 645 of 26.10.2020. The main vector of the region's development is the preservation of the natural conditions of the Arctic zone and the well-being of the indigenous population. The prospects for the development of the Arctic zone include the following:

the development of digital technologies in the field of mining and oil refining industry, the use of telecommunications to control technological processes in industry will reduce the share of heavy physical labor, reduce the time of performing labor operations [17]. In conditions of lack of labor resources and the need to minimize the anthropogenic negative impact on nature. Digitalization of the industry can be the best solution;

innovative technologies in crop and animal husbandry will allow indigenous peoples to create jobs, facilitate work and improve the quality of life. Fishing and animal husbandry are traditional activities of the indigenous peoples of the North. Training the indigenous population in new technologies and professional skills will help to interest the younger generation in the development of basic activities;

it is necessary to create conditions for indigenous people to receive higher education in their native region in the specialties that are in demand and necessary for the development of traditional activities. The connection with ethnic traditions leaves an imprint on all spheres of life of the indigenous nationalities of the Arctic. Getting an education requires a special vacation mode and a format of interaction with teachers. Digitalization of education will help representatives of indigenous nationalities to get an education without leaving the area of residence;

issues of environmental safety of the region should be resolved jointly with representatives of the regional administration, federal authorities and representatives of the indigenous population;

the use of the transport arteries of the Arctic zone to solve new problems for the development of new tourist destinations is transforming the activities of the Northern Sea Route and cross-Arctic air travel. The development of new logistics opportunities is associated with the modernization and renewal of transport hubs [18]. The largest and most famous - Murmansk, Pevek, Tiksi, Dixon, Dudinka. The Murmansk Region, which has historically been the "gateway" to the Arctic, can act as the flagship of Russian cruise tourism; 
Ecotourism and ethnographic tourism are promising areas for the Arctic. Ecotourism implies minimal anthropogenic impact on the places of residence and promotes the preservation of natural objects. Ethnographic tourism involves direct "immersion" of participants in the original culture of the small indigenous peoples of the Arctic, which will allow them to transfer their rich cultural heritage to other cultures and will contribute to the development of public interest in the life of the indigenous population [19].

To ensure the preservation of the Arctic ecological system in the industrial development of natural resources and the development of enterprises in the region in accordance with the state strategy for the development of the region, investments in fixed assets for the protection and restoration of natural resources are increasing. A comparative analysis of investments from 2017 to 2019 is presented in figure 3.

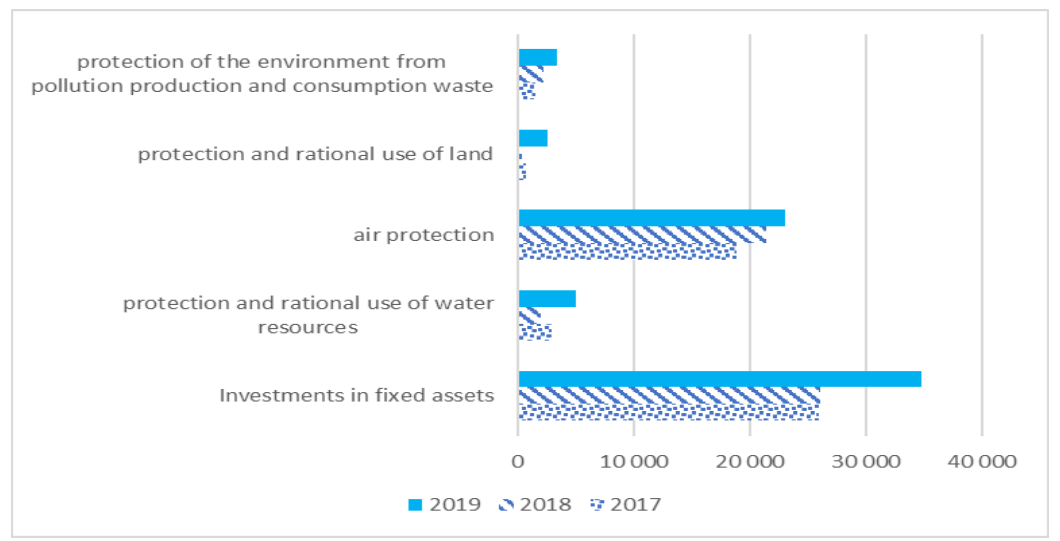

Fig. 3. Investments in fixed assets for environmental protection (millions of rubles).

As shown in Figure 3, there is an increase in investment in fixed assets in all areas of environmental protection to minimize anthropogenic impact: protection and rational use of water resources, protection of atmospheric air; protection and rational use of land; protection of the environment from pollution by production and consumption waste. The trend of increasing investment in the protection of the natural resources of the Arctic zone of the Russian Federation allows us to predict the development of the region in accordance with modern environmental requirements.

\section{Conclusions}

The development of the Arctic economy with the preservation and protection of the unique natural environment allows us to identify the following promising areas:

- development of raw materials industries, mining in combination with the environmental responsibility of enterprises engaged in the extraction of raw materials. The analysis of the amount of recycled waste by enterprises of the Arctic zone suggests that in 2019 , compared to 2017, the amount of recycled industrial waste increased 33 times. This fact testifies to the increased environmental responsibility of industrial enterprises in the Arctic. The data is shown in the figure 4; 


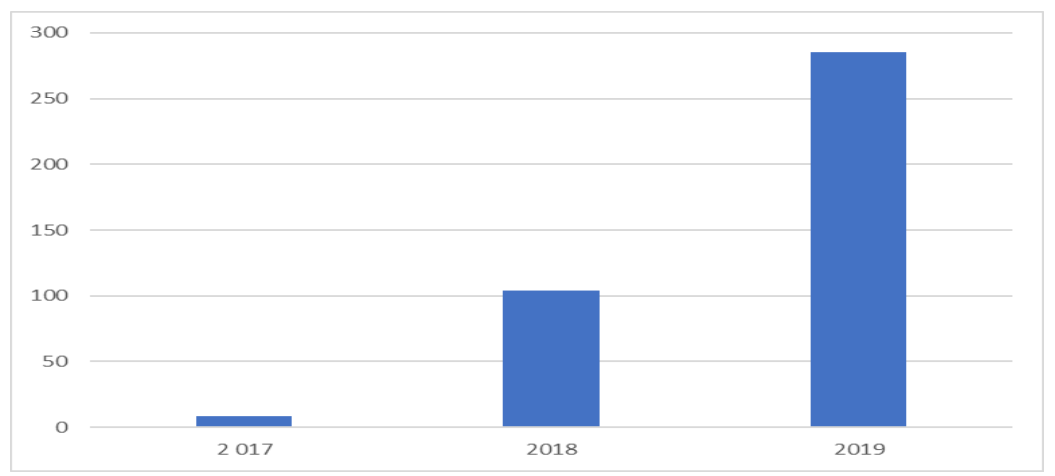

Fig. 4. Wastes of production and consumption processed (thousand tons).

- development of the human potential of the indigenous peoples of the Arctic is linked to the maintenance of the natural environment in which they live and engage in traditional animal husbandry. Support for traditional activities of the local population is associated with land reclamation. Figure 5 shows that the amount of reclaimed land increased by 2 times from 2017 to 2019 .

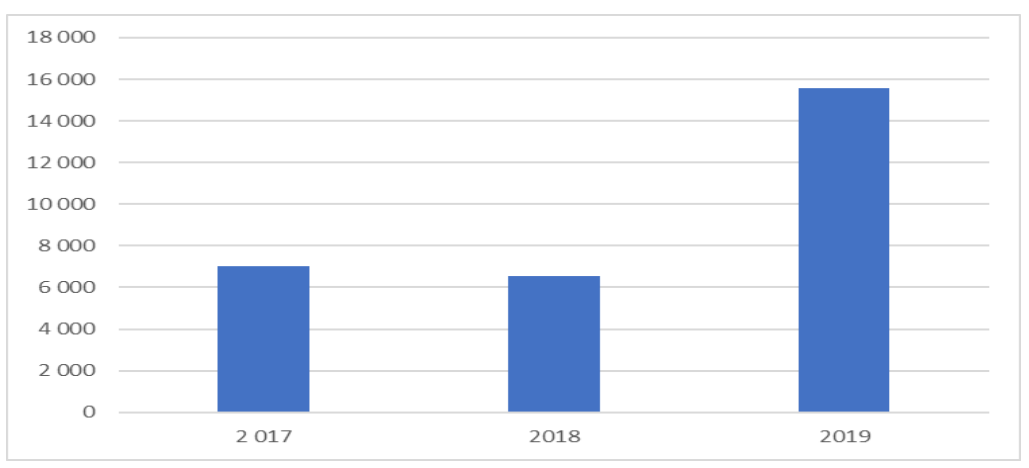

Fig. 5. Reclaimed land (for 1 year; hectares).

This confirms the trend towards the preservation and increase in the number of indigenous peoples. Preservation and maintenance of not only the ecological system, but also the cultural heritage of the population historically living in the Arctic;

- the modernization of the transport arteries of the Arctic zone to meet new challenges will change the direction of the Northern Sea Route and cross-Arctic air travel. The renewal of transport hubs will help to develop the region's economy and minimize the negative impact on the environment;

- the development of digital technologies in industry, the use of telecommunications to control technological processes will facilitate the work of employees and reduce the need for labor resources [20];

- the preservation of unique natural conditions that are of global value is a unique resource for ecological and extreme tourism.

The Arctic zone of the Russian Federation combines factors that need to be taken into account in the future development of the region. The ethos is a lack of labor, difficult climatic conditions, a unique ecological system and the identity of the indigenous population. The integration of the rich natural potential of the region with the listed features will ensure the economic development of the region while maintaining the balance of the ecological system. 


\section{References}

1. I. Krasyuk, T. Kirillova, N. Kozlova, Web of Conferences 35, 01055 (2017)

2. I. Kapustina, T. Kirillova, O. Ilyina, O. Razzhivin, P. Smelov, International Journal of Applied Business and Economic Research 15 (11), 1-10 (2017)

3. E. Korchagina, L. Desfonteines, Internal resources of increasing retail efficiency. Intellectual Economics 13(2), 122-130 (2019). doi: 10.13165/IE-19-13-2-03

4. S.Sergeev, T.Kirillova, I.Krasyuk, E3S Web of Conferences, 05007 (2019)

5. B.M. Lyamin, I.A. Krasyuk, Smart Innovation, Systems and Technologies 139 (2018) https://doi.org/10.1007/978-3-030-18553-4 49

6. L. Desfonteines, E. Korchagina, A. Varnaev, J. Semenova, Organizational culture of trade enterprises in the context of modern demographic challenges and the use of information technology. Proceeding of the $2 \mathrm{~d}$ International Scientific Conference on Digital Transformation on Manufacturing, Infrastructure and Service (DTMIS). In: IOP Conference Series: Materials Science and Engineering. vol. 497 (1). (2019) 012117. https://doi.org/10.1088/1757-899X/497/1/012117

7. I. Asfondiarova, V. Demchenko, K. Illarionova, E. Kravtsova, IOP Conference Series: Materials Science and Engineering 497(1) (2019) 012106 doi:10.1088/1757$899 X / 497 / 1 / 012106$

8. L. Desfonteines, E. Korchagina, Study of Gender Structure of the Russian Labor Market. In: Proceedings of the 33d International Business Information Management Association Conference, IBIMA 2019: Education Excellence and Innovation Management through Vision 2020, pp. 2216-2221 (2019)

9. O. Lukina, A. Kurochkina, A. Karmanova, E3S Web of Conferences 175 (2020) doi: $10.1051 / \mathrm{e} 3$ sconf $/ 202017510010$

10. Official website of the Federal state service. Calendar of publication of official statistical information on the socio-economic development of the Arctic zone of the Russian Federation in 2020. (2020) URL: https://gks.ru/free doc/new site/region stat/calendar1-2020.htm (access date 04.2021)

11. Natural resources of the Arctic. (2010) URL: https://ria.ru/20100415/220120223.html (access date 05.2021)

12. E. Korchagina, L. Desfonteines, N. Strekalova, E3S Web of Conferences 164, 12014 (2020). doi: 10.1051/e3sconf/202016412014

13. I. Krasyuk, Y.Medvedeva, V. Baharev, G. Chargaziya, IOP Conference Series: Materials Science and Engineering 497 (1), 012124 (2019)

14. Official website of the Federal state service. Environmental Protection in Russia. M., 0-92 (2020)

15. E. Korchagina, R. Shignanova, Study of the North Baikal region attractiveness for domestic tourism development. Proceedings of the 31st International Business Information Management Association Conference, IBIMA 2018: Innovation Management and Education Excellence through Vision 2020, pp. 2994-3003 (2018)

16. N. Strekalova, E. Korchagina, L. Desfonteines, E3S Web of Conferences 164, 09020 (2020). doi: 10.1051/e3sconf/202016409020

17. E. Korchagina, L. Desfonteines, A. Kurochkina, M. Sobotka, L. Sobotková, N. Strekalova, IOP Conf. Ser.: Mater. Sci. Eng. 940, 012050 (2020) https://doi.org/10.1088/1757-899X/940/1/012050 
18. S. Sergeev, T. Kirillova, IOP Conference Series: Materials Science and Engineering. International Scientific-Practical Conference on Quality Management and Reliability of Technical Sytems, 012064 (2019)

19. L. Desfonteines, Y. Semenova, The role of social networks in the political life of society. Proceedings of the 33rd International Business Information Management Association Conference, IBIMA 2019: Education Excellence and Innovation Management through Vision 2020, pp. $4582-4585$ (2019)

20. L. Desfonteines, E. Korchagina, A. Evgrafov, T. Khnykina, A. Karmanova, Y. Semenova, IOP Conf. Ser.: Mater. Sci. Eng. 940 (1), 012058 (2020)

https://doi.org/10.1088/1757-899X/940/1/012058 